\title{
Letter from the Guest Editor
}

\author{
Yuei-An Liou
}

Published online: 20 November 2009

(C) Springer-Verlag 2009

The FORMOSAT-3/COSMIC mission, launched on April 15, 2006, is a joint Taiwan-US mission for meteorological, climatological, ionospheric, and geodetic studies. It consists of a constellation of six satellites, each equipped with GPS antennas for precise orbit determination (POD) and radio occultation (RO) experiments. Its successful deployment provides the first ever largest volume of RO data distributed globally and almost uniformly, thus overcoming two limitations of previous RO missions: sparcity and scarcity of occultation data. The previous RO missions include CHAMP (2000), SAC-C (2000), GRACE-A (2002), METOP (2006), and TerraSAR/TanDEM-X (2007).

Twelve papers in this special issue describe new results that modernize RO methods and extend the applicable domain. The papers are ordered according to topic: RO methodologies, weather/climate, ionosphere/space, and geodesy. (1) Pavelyev et al. utilize phase acceleration instead of Doppler frequency to convert the RO observations to the atmospheric profiles of interest. (2) Schreiner et al. evaluate the quality of GPS RO atmospheric excess phase data derived with single- and double-difference processing algorithms. (3) Aragon-Angel et al. propose an improved Abel transform inversion using derived bending angles. (4) Huang et al. analyze the impact of GPS RO data assimilation on regional weather predictions. (5) Chien and Kuo examine the impact of GPS RO and dropwindsonde data on regional model predictions over an 11-day period during the 2007 Mei-yu season. (6) Xiao and $\mathrm{Hu}$ present the global morphology of stratospheric gravity wave activity deduced from the COSMIC GPS occultation profiles. (7) Liu et al. compare electron density profiles in the equatorial ionosphere observed by the FORMOSAT-3/ COSMIC and a digisonde at Jicamarca. (8) Hsiao et al. investigate the seismo-ionospheric precursor of the 2008 Mw7.9 Wenchuan earthquake observed by FORMOSAT3/COSMIC. (9) Tsai et al. utilize the FORMOSAT-3/ COSMIC observations to study the ionospheric auroral oval development. (10) Wang et al. study ionospheric electron parameters versus geomagnetic index Dst from FORMOSAT-3/COSMIC. (11) Bonnedal et al. present results of a data analysis from an onboard instrument perspective. (12) Hwang et al. provide quality assessment of the FORMOSAT-3/COSMIC and GRACE GPS observables and analysis of multipath, ionospheric delay and phase residual in orbit determination.

The special issue captures the fundamental principles, achievements, and practices developed during the last ten years of RO investigations of the earth's atmosphere. It will serve as a guide for the scientists and engineers working on the scientific and technological problems of space borne RO remote sensing.

I am very grateful to the reviewers for their valuable time and efforts. Special thanks are due to Prof. Alfred Leick (Editor-in-Chief) and Prof. Alexander G. Pavelyev for their help in the preparation of this special issue.

Yuei-An Liou, Guest Editor
Y.-A. Liou $(\bowtie)$

Center for Space and Remote Sensing Research, National Central University, Chung-Li 320, Taiwan e-mail: yueian@csrsr.ncu.edu.tw 


\section{Author Biography}

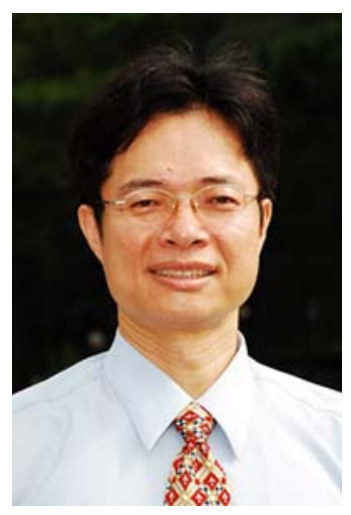

Yuei-An Liou received the B.S. degree in electrical engineering from National Sun Yat-Sen University, Kaohsiung, Taiwan, the M.S.E. degree in electrical engineering (EE), the M.S. degree in atmospheric and space sciences, and the Ph.D. degree in EE and atmospheric, oceanic, and space sciences from the University of Michigan, Ann Arbor, in 1987, 1992, 1994, and 1996 , respectively. He is professor and the director of the Center for Space and Remote Sensing Research (CSRSR), National Central University, Taiwan. He was awarded Honorary Life Member of The Korean Society of
Remote Sensing (2007), elected Foreign Member, Prokhorov Academy of Engineering Sciences, Russian Federation (2008), awarded Outstanding Alumni Awards by University of Michigan Alumni Association in Taiwan and National Sun Yat-sen University (2008), and elected Academician, International Academy of Astronautics (2009). 